\title{
Modeling ANd ANAlysis OF DeliVery PlanNing in SuPPly Chain
}

\author{
MiWA, K.
}

Abstract: This paper describes modeling and analysis of delivery planning in supply chain. A delivery planning and a simulation model between a distribution center and retailers was designed and built from the viewpoint of "the flow of a thing" in a supply chain for a specific corporate activity which performs production and distribution of daily consumer goods. In distribution center, they focus on the flow of information in connection with delivery requests and truck deliveries. To make the delivery routes, this proposed system used modified saving method with multiple constraints. In this paper, with regards to trucking, there exits three constraints in terms of transport time including the weight of the freight, capacity, and the working hours that are used by the retailer in final delivery (from shipping and discharging of a product to delivery of goods) are taken into consideration. The saving method which represents one of the heuristics techniques for vehicle routing problems was modified and applied in solving delivery route problems by using Excel-VBA. Such a system allows decision-makers to examine the situation of deliveries visually, for example, seeing the routes of trucks built on a map with an animation.

Key words: simulation, vehicle routing problem, delivery planning, supply chain, optimization
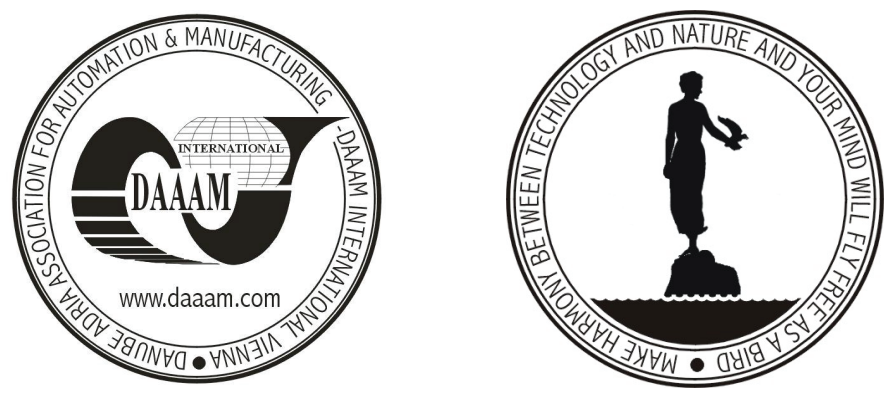

Authors' data: Miwa K.[anna], Graduate School of Economics and Business Administration Nagoya University, Japan, kanna@quartz.ocn.ne.jp

This Publication has to be referred as: Miwa, K. (2006). Modeling and Analysis of Delivery Planning in Supply Chain, Chapter 33 in DAAAM International Scientific Book 2006, B. Katalinic (Ed.), Published by DAAAM International, ISBN 3-90150947-X, ISSN 1726-9687, Vienna, Austria

DOI: $10.2507 /$ daaam.scibook.2006.33 